\title{
First report of Blastocystis spp. subtypes in ZOO animals in Slovakia, Central Europe
}

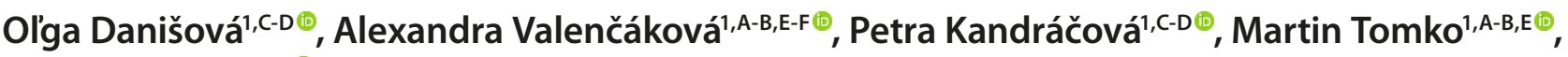 \\ Monika Sučik ${ }^{1, C, E-F \oplus}$
}

1 University of Veterinary Medicine and Pharmacy, Košice, Slovak Republic

A - Research concept and design, B - Collection and/or assembly of data, C - Data analysis and interpretation,

$D$ - Writing the article, E-Critical revision of the article, $F$ - Final approval of the article

Danišová O, Valenčáková A, Kandráčová P, Tomko M, Sučik M. First report of Blastocystis spp. subtypes in ZOO animals in Slovakia, Central Europe. Ann Agric Environ Med. 2022; 29(1): 149-151. doi: 10.26444/aaem/145826

\begin{abstract}
I Abstract
Blastocystis spp. has been reported in wildlife, domestic animals and animals housed in ZOO. To-date, 17 genetically diverse lines have been reported in mammals and birds (designated ST) based on differences in the SSU rRNA. In this study, faeces samples were collected from $24 \mathrm{ZOO}$ animals with clinical signs suggestive of gastrointestinal disease in Košice ZOO, Slovakia. After DNA isolation, PCR was conducted to amplify the SSU region of DNA of Blastocystis species. Forward primer- Blast F and reverse primer- Blast $\mathrm{R}$ were used in the reaction. From 25 faeces samples, Blastocystis spp. was detected in 5 animals ( 3 mammals, 2 birds), with a prevalence of $20 \%$. Subsequent molecular analyses identified the ST $5(n=3)$, ST $7(n=1)$, and ST $12(n=1)$ subtypes, where the ST 5 subtype was identified in the mammalian group and birds, and the ST 7 and ST 12 subtypes were identified only in mammals. Based on these findings, focusing on ZOO animals as a potential source of infection for humans is highly recommended.
\end{abstract}

I Key words

PCR, Slovakia, Blastocystis spp., subtypes, ZOO animals

\section{INTRODUCTION}

Blastocystis spp. is an unicellular microorganism found in the gastrointestinal tract of humans and various animals, including primates, amphibians, reptiles, and even insects $[1,2,3,4,5]$. Although samples taken from infected humans and animals were morphologically indistinguishable from each other, a remarkable genetic diversity between samples from both humans and animals was demonstrated $[2,6]$. To-date, 17 genetically diverse lines have been reported in mammals and birds (subtypes; designated ST) based on differences in the small subunit of ribosomal RNA (SSU rRNA) [7]. Blastocystis spp. has a wide range of hosts, with the same subtype found in several animal species. Ten of the 17 STs (ST1 - ST10) were detected in humans, while ST 9 was identified only in humans, which can be considered a human-specific subtype. Blastocystis spp. has been reported in wildlife, domestic animals, and ZOO animals $[3,8,9,10$, $11,12]$, and several authors have described the distribution of Blastocystis spp. among animals in ZOOs [2, 3, 13]. The diversity of subtypes of Blastocystis spp. in animals in such a small area as aOO is an alarming fact. Infected animals are a threat not only to other species but also to staff and visitors $[13,14]$. Therefore, additional epizootiologic data need to be provided to identify potential sources of Blastocystis infection in animals, which was also the aim of this ZOO animal study.

Address for correspondence: Alexandra Valenčáková, University of Veterinary Medicine and Pharmacy, Košice, Slovak Republic

E-mail: alexandra.valencakova@uvlf.sk

Received: 09.06.2021; accepted: 13.01.2022; first published: 27.01.2022

\section{MATERIALS AND METHOD}

Study population - samples. Samples of faeces were collected from 24 animals ( 9 mammals, 15 birds, Tab.1) in the ZOO in Košice, Slovakia. Faecal samples were collected only from animals with clinical signs of gastrointestinal disease (anorexia, diarrhoea, abdominal pain, and weight loss to cachexia).

DNA isolation, PCR, electrophoresis, sequencing. The procedure for DNA isolation, subsequent PCR, electrophoresis and sequencing, followed the protocol according to Danišová et al. (2021) [15].

\section{RESULTS}

In 25 faeces samples, Blastocystis spp. was detected in 5 animals (3 mammals, 2 birds), with a prevalence of $20 \%$. Subsequent molecular analyses identified the ST $5(n=3)$, ST $7(\mathrm{n}=1)$, and ST $12(\mathrm{n}=1)$ subtypes. The ST 5 subtype was detected in the mammalian and bird groups, and the ST 7 and ST 12 subtypes only in mammals. Five sequences identified by the sequencing service and evaluated by BLAST as Blastocystis spp. were used to create a phylogenetic tree. There were also 29 sequences of 16 individual subtypes stored in GenBank, 2 sequences of the group Katotomorpha spp. DQ431243 and Protoopalina intestinal AY576545. The comparison and placement of branches in the phylogenetic tree confired the identification of individual subtypes (Fig. 1). The sequences identified in this study were deposited in the GenBank database (Accession Nos. OK431085, OK431086, OK431087, OK431088, OK431089) (Tab. 1). 


\section{DISCUSSION}

In the authors'epizootiologic survey, mammalian and bird animal groups were represented. Primates were the most tested animals in the group of mammals due to their high incidence of this disease worldwide. In Italy, there was the highest prevalence of Blastocystis spp. in long-tailed macaques $87.6 \%$ [16], in Ecuador, the majority of this species reached $60.4 \%$ in a group of monkeys [17], and Tanzania reported a prevalence of $49 \%-51.3 \%$ in wild chimpanzee communities and $71.4 \%$ to $92 \%$ in monkeys $[18,19,20]$. In the current study, Blastocystis spp. was found in 2 of the 5 examined primates, which represents a prevalence of $40 \%$. In a group of other tested mammals (Tab. 1), blastocystosis was confirmed in a single wild boar, which suggests that the detection of blastocystosis in wild animals is difficult because of their free movement in nature. A study conducted by Danišová et al. in Slovakia (2021) [15], also focused on identifying this

Table 1. Species of tested animals and suptypes found.

\begin{tabular}{|c|c|c|c|}
\hline Isolate & Mammals & $\begin{array}{l}\text { Blastocystis } \\
\text { sp./subtype }\end{array}$ & $\begin{array}{c}\text { GenBank } \\
\text { Accession } \\
\text { Nos. }\end{array}$ \\
\hline 1 przewalski's horse & Equus ferus przewalskii & & \\
\hline 2 bactrian camel & Camelus bactrianus & & \\
\hline 3 wild boar & Sus scrofa & & \\
\hline 4 wild boar & Sus scrofa & $\begin{array}{l}\text { Blastocystis } \\
\text { ST } 12\end{array}$ & OK431086 \\
\hline 5 tufted capuchin & Sapajus apella & & \\
\hline 6 patas monkey & Erythrocebus patas & & \\
\hline 7 barbary macaque & Macaca sylvanus & & \\
\hline 8 ring-tailed lemur & Lemur catta & $\begin{array}{l}\text { Blastocystis } \\
\text { ST } 7\end{array}$ & OK43108 \\
\hline $\begin{array}{l}9 \text { black-and-white } \\
\text { ruffed lemur }\end{array}$ & $\begin{array}{c}\text { Varecia variegata } \\
\text { variegata }\end{array}$ & Blastocystis ST5 & OK431085 \\
\hline & Birds & & \\
\hline $\begin{array}{l}10 \text { spur-winged } \\
\text { goose }\end{array}$ & $\begin{array}{l}\text { Plectropterus gambensis } \\
\text { gambensis }\end{array}$ & & \\
\hline $\begin{array}{l}11 \text { spur-winged } \\
\text { goose }\end{array}$ & $\begin{array}{l}\text { Plectropterus gambensis } \\
\text { gambensis }\end{array}$ & & \\
\hline $\begin{array}{l}12 \text { southern ground } \\
\text { hornbill }\end{array}$ & Bucorvus leadbeateri & & \\
\hline 13 papuan hornbill & $\begin{array}{l}\text { Rhyticeros plicatus } \\
\text { ruficollis }\end{array}$ & & \\
\hline $\begin{array}{l}14 \text { marabou stork } \\
\text { (male) }\end{array}$ & Leptoptilos crumeniferus & Blastocystis ST5 & OK431088 \\
\hline $\begin{array}{l}15 \text { marabou stork } \\
\text { (female) }\end{array}$ & Leptoptilos crumeniferus & & \\
\hline 16 emu & Dromaius novaehollandiae & & \\
\hline 17 emu & Dromaius novaehollandiae & & \\
\hline $18 \mathrm{emu}$ & Dromaius novaehollandiae & & \\
\hline 19 mandarin duck & Aix galericulata & & \\
\hline 20 bernier's teal & Anas bernieri & Blastocystis ST5 & OK43108 \\
\hline $\begin{array}{l}\mathbf{2 1} \text { white-winged } \\
\text { duck }\end{array}$ & Asarcornis scutulata & & \\
\hline 22 eurasian spoonbill & Platalea leucorodia & & \\
\hline 23 little egret & Egretta garzetta & & \\
\hline \multirow[t]{2}{*}{24 greater rhea } & Rhea americana & & \\
\hline & $\Sigma \mathrm{ZOO}$ animals & 5 & \\
\hline
\end{tabular}

pathogen. The highest prevalence of Blastocystis spp. has been reported in birds (up to 82\%), making them the highest risk for humans. ZOO birds, however, show a much lower prevalence, presumably due to more frequent cleaning their cages and runs than other animals, as confirmed by other surveys $[13,21,22]$. In the current study, Blastocystis spp. was identified only in 2 of the 15 samples collected from birds (13.3\%), consistent with study results worldwide.

Out of the 17 Blastocystis ST, subtypes ST1-ST8, ST10, ST13- ST15, and ST17 have been identified worldwide, with varying prevalence among groups of animals. The huge genetic diversity of Blastocystis spp. was also pointed out among the animals in the ZOO $[2,4,21,23]$. In this study, of the 25 analyzed samples, 3 subtypes were identified. In Košice ZOO, the waterfowl of the avian group is located at 2 different places (Fig. 2). The most commonly found subtypes of Blastocystis spp. in birds are ST6 and ST7, characterized as 'avian' [6, 24]. However, ST1, ST4, and ST5 have also been identified in ZOO animals; ST5 is the most often presented in pigs. ST 12 was found in a positive wild boar's sample, which is typical for ruminants [3].

The third subtype - ST7, was identified in Lemur catta and ST5 was also identified in black and white ruffed lemur (Varecia variegata variegata). These 2 primates are placed next to each other, although different subtypes of Blastocystis were identified (Fig 1, Fig 2). Worldwide, ST1-ST8 subtypes have been detected in primates, and interestingly, animal isolates of all the isolated subtypes have been matched to isolates from stool samples in members of staff $[2,14,25]$.

\section{CONCLUSION}

This study is the first in Slovakia to deal with Blastocystis spp., in $\mathrm{ZOO}$ animals. The results indicate the need to focus on ZOO animals as a potential source of infection for humans $[13,23]$. These are, in particular, the zoonotic subtypes ST5 and ST7, which have been identified in primates that are close to care keepers, or the subtype ST5 in waterfowl, where visitors can also be in the proximity of the animals. These data

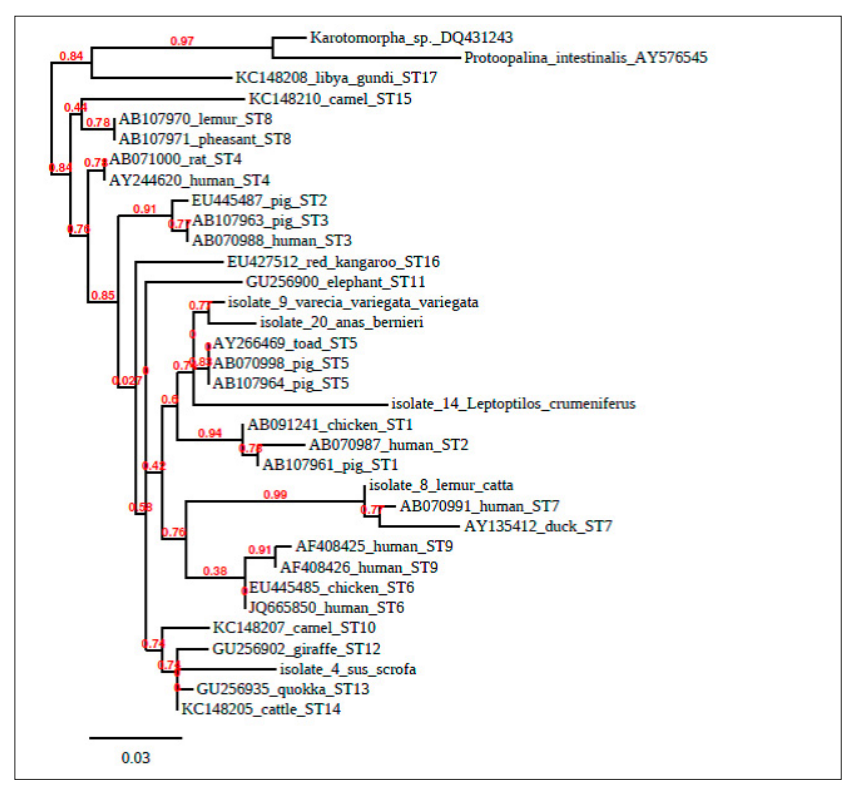

Figure 1. Branches in the phylogenetic tree confirming the identification of individual subtypes 


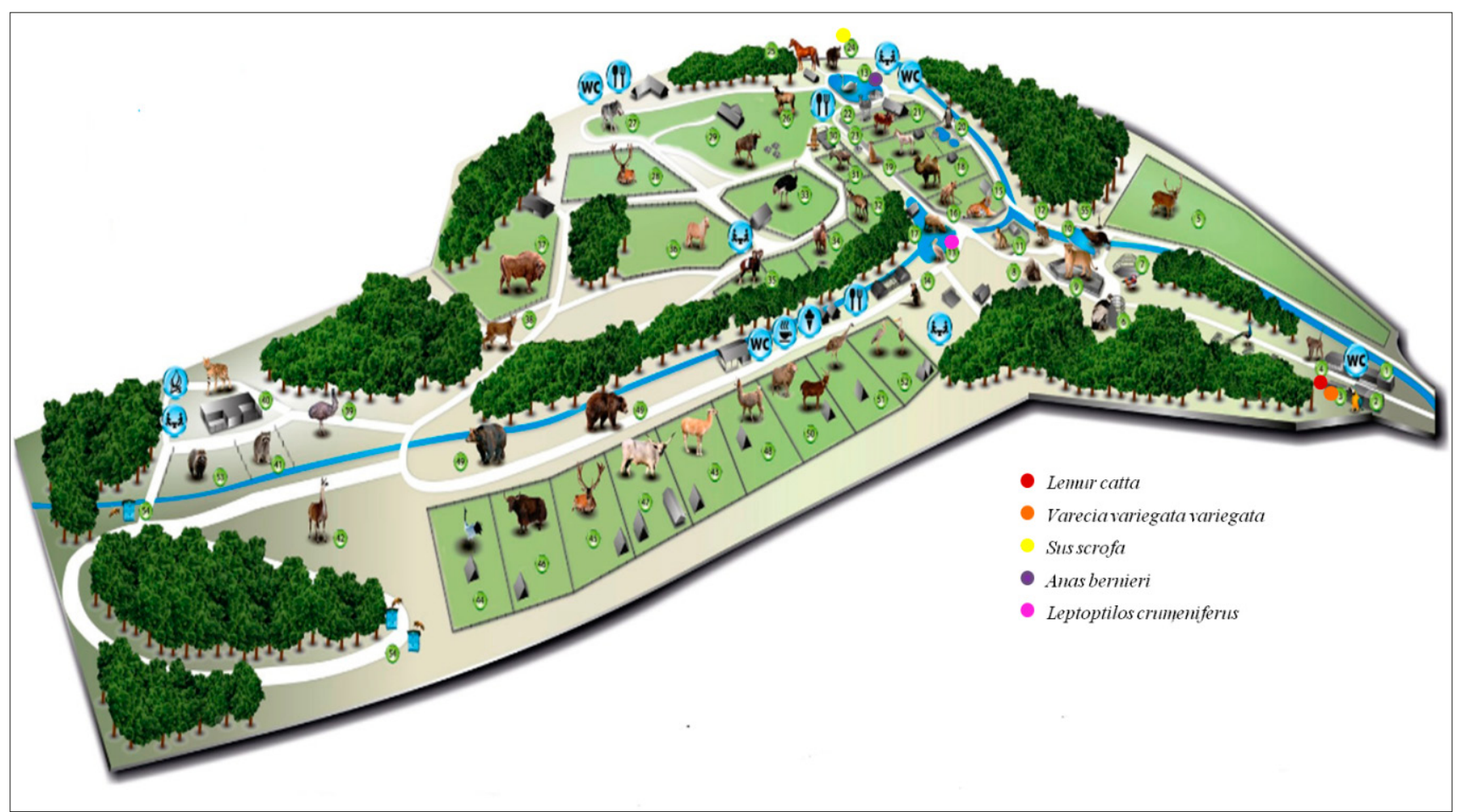

Figure 2. Map of the ZOO Košice

also emphasize the importance of screening other Blastocystis spp. hosts to broaden epizootiological and epidemiological information on the occurrence of this parasite, and to take preventive and control measures to help reduce the incidence of Blastocystis spp. in ZOO animals, and thus minimize the risk of transmission of the zoonosis from animals to staff.

\section{Funding Statement}

This project was created with the support of the grant project of the Ministry of Education, Science, Research and Sport of the Slovak Republic VEGA no. 1/0113/20.

\section{REFERENCES}

1. Abe N. Molecular and phylogenetic analysis of Blastocystis isolates from various hosts. Vet Parasitol. 2004; 120(3): 235-242.

2. Stensvold CR, et al. Subtype distribution of Blastocystis isolates from synanthropic and $\mathrm{ZOO}$ animals and identification of a new subtype. Int J Parasitol. 2009; 39(4): 473-9.

3. Parkar U, et al. Molecular characterization of Blastocystis isolates from ZOO animals and their animal-keepers. Vet Parasitol. 2010; 169(1-2): 817.

4. Roberts T, et al. Subtype distribution of Blastocystis isolates from a variety of animals from New South Wales, Australia. Vet Parasitol. 2013; 196(1-2): 85-9.

5. Yoshikawa H, Iwamasa A. Human Blastocystis subtyping with subtypespecific primers developed from unique sequences of the SSU rRNA gene. Parasitol Int. 2016; 65(6 Pt B): 785-791.

6. Noel C, et al. Molecular phylogenies of Blastocystis isolates from different hosts: implications for genetic diversity, identification of species, and zoonosis. J Clin Microbiol. 2005; 43(1): 348-55.

7. Betts EL, Gentekaki E, Tsaousis AD. Exploring Micro-Eukaryotic Diversity in the Gut: Co-occurrence of Blastocystis Subtypes and Other Protists in ZOO Animals. Front Microbiol. 2020;11:288. Published 2020 Feb 25. doi:10.3389/fmicb.2020.00288

8. Ramirez JD, et al. Geographic distribution of human Blastocystis subtypes in South America. Infect Genet Evol. 2016; 41: 32-35.

9. Ruaux CG, Stang BV. Prevalence of blastocystis in shelter-resident and client-owned companion animals in the US Pacific Northwest. PLoS One. 2014; 9(9): e107496.
10. Schar F, et al. The prevalence and diversity of intestinal parasitic infections in humans and domestic animals in a rural Cambodian village. Parasitol Int. 2014; 63(4): 597-603.

11. Figueroa J. New records of parasites in free-ranging Andean bears from Peru. Ursus. 2015; 26(1): 21-27.

12. Puebla LEJ, et al. Prevalence of intestinal parasites and molecular characterization of Giardia duodenalis from dogs in La Habana, Cuba. Vet Parasitol Reg Stud Reports. 2017; 8: 107-112.

13. Betts EL, et al. Genetic diversity of Blastocystis in non-primate animals. Parasitol. 2018; 145(9): 1228-1234.

14. Alfellani MA, et al. Genetic diversity of blastocystis in livestock and ZOO animals. Protist. 2013; 164(4): 497-509.

15. Danisova O, Valencakova A. First detection of Blastocystis sp. in pigs in Slovakia and in Europe. Parasitol Int. 2021; 81: 102235.

16. Zanzani SA, et al. Study of the gastrointestinal parasitic fauna of captive nonhuman primates (Macaca fascicularis). Parasitol Res. 2016; 115(1): 307-12.

17. Helenbrook WD, Shields WM, Whipps CM. Characterization of Blastocystis species infection in humans and mantled howler monkeys, Alouatta palliata aequatorialis, living in close proximity to one another. Parasitol Res. 2015; 114(7): 2517-2525.

18. Kalousova B, et al. Gastrointestinal Parasites of Savanna Chimpanzees (Pan troglodytes schweinfurthii) in Ugalla, Tanzania. Int J Primatol. 2014; 35(2): 463-475.

19. Petrasova J, et al. Diversity and host specificity of Blastocystis in syntopic primates on Rubondo Island, Tanzania. Int J Parasitol. 2011; 41(11): 1113-20.

20. Abe N, et al. A survey of Blastocystis sp. in livestock, pets, and ZOO animals in Japan. Vet Parasitol. 2002; 106(3): 203-12.

21. Alfellani MA, et al. Diversity and distribution of Blastocystis sp. subtypes in nonhuman primates. Parasitol. 2013; 140(8): 966-71.

22. Cian A, et al. Molecular Epidemiology of Blastocystis sp. in Various Animal Groups from Two French Zoos and Evaluation of Potential Zoonotic Risk. PLoS One. 2017; 12(1): e0169659.

23. Li XD, et al. Prevalence and subtypes of Blastocystis sp. infection in ZOO animals in three cities in China. Parasitol Res. 2020; 119(2): 465-471.

24. Alfellani MA, et al. Variable geographic distribution of Blastocystis subtypes and its potential implications. Acta Trop. 2013; 126(1): 11-8.

25. Parkar U, et al. Direct characterization of Blastocystis from faeces by PCR and evidence of zoonotic potential. Parasitol. 2007; 134(Pt 3): $359-67$. 